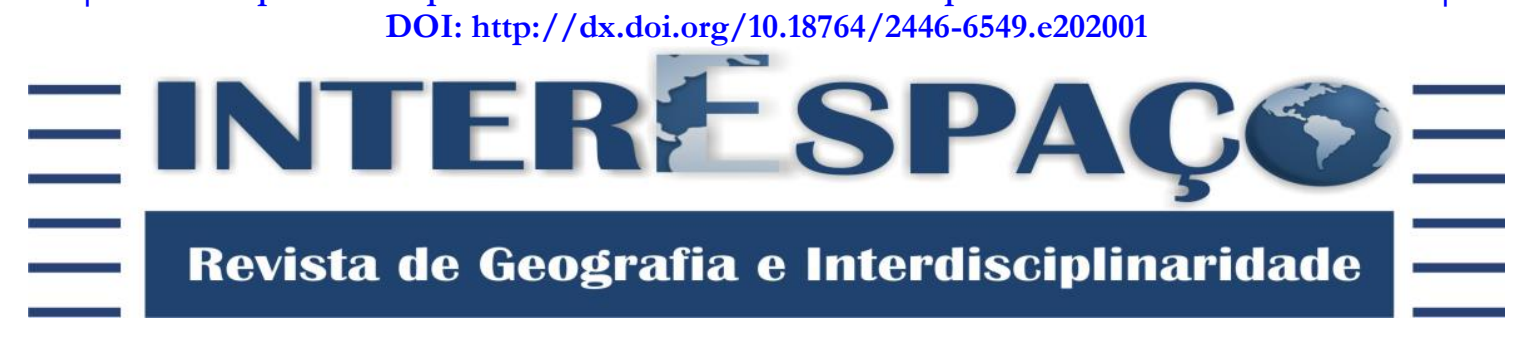

\title{
ZONA FRANCA DE MANAUS: uma revisão sistemática de impactos
}

MANAUS FREE TRADE ZONE: a systematic review of impacts

ZONA FRANCA DE MANAOS: una revisión sistemática de impactos

\author{
Luiz Ricardo Cavalcante \\ Doutor em Administração pela Universidade Federal da Bahia - UFBA. Consultor legislativo do \\ Senado Federal. Professor do Mestrado em Administração Pública do Instituto Brasileiro de \\ Ensino, Desenvolvimento e Pesquisa - IDP. \\ luiz.ricardo.teixeira.cavalcante@gmail.com / http://orcid.org/0000-0003-1894-7238.
}

Recebido para avaliação em 01/07/2020; Aceito para publicação em 21/09/2020.

\begin{abstract}
RESUMO
Embora criada há mais de meio século, a Zona Franca de Manaus (ZFM) tem sido objeto de um número relativamente escasso de análises de seus impactos econômicos e sociais. O objetivo deste artigo é apresentar uma revisão sistemática das principais estatísticas e dos principais resultados de trabalhos selecionados sobre o tema. Buscou-se identificar trabalhos que ultrapassam a descrição da evolução das variáveis por meio, por exemplo, do uso de contrafactuais, regressões econométricas ou modelos de equilíbrio geral. A análise é precedida por uma breve revisão da literatura sobre zonas econômicas especiais (ZEE). Os resultados indicam que i) a ZFM tem impactos positivos nos níveis de renda e de bem-estar em Manaus, ainda que essa conclusão não seja unânime; ii) não há evidências conclusivas de que a ZFM contribui para a preservação ambiental da Amazônia; iii) os gastos tributários da União dirigidos à ZFM são estimados em $\mathrm{R} \$ 28,7$ bilhões (mais de $\mathrm{R} \$ 380$ mil por emprego direto gerado); e iv) embora o foco das ZEE recaia, de modo geral, sobre as exportações, o caso da ZFM é, em grande medida, singular em razão de seu foco no mercado interno. A ZFM é, portanto, do ponto de vista legal e do ponto de vista prático, essencialmente uma política de desenvolvimento regional (e não uma política de incentivo às exportações) e as análises sobre o tema devem amparar-se nessa premissa.
\end{abstract}

Palavras-chave: Zona Franca de Manaus; Zonas Econômicas Especiais; Impactos; Gastos Tributários; Políticas de Desenvolvimento Regional.

\section{ABSTRACT}

Although created more than half a century ago, the Manaus Free Trade Zone (MFTZ) has been subject of a relatively reduced number of analysis of its economic and social impacts. The aim of this work is to present a systematic review of the man statistics and of the main results of a number of selected works about this subject. We sought to identify studies that go beyond the description of the evolution of variables through, for example, the use of counterfactuals, econometric regressions or general equilibrium models. The analysis is preceded by a brief review of the literature on special economic zones (SEZ). The results indicate that i) the MFTZ has positive impacts on the levels of income and well-being in Manaus, although this conclusion is not unanimous; ii) there is no conclusive evidence that the ZFM contributes to the environmental preservation of the Amazon; iii) federal tax expenditures directed to the ZFM are estimated in R\$ 28.7 billion (more than $\mathrm{R} \$ 380$ thousand for direct employment generated); and $i v$ ) although the focus of SEZ falls, in general, on exports, the case of MFTZ is largely unique due to its focus on the domestic market. The MFTZ is, therefore, both legally and in practice, essentially a regional 
| Luiz Ricardo Cavalcante |

development policy (and not an export incentive policy) and the analyzes on the subject must be based on this assumption.

Keywords: Manaus Free Trade Zone; Special Economic Zones; Impacts; Tax Expenditures; Regional Development Policies.

\section{RESUMEN}

Aunque creada hace más de medio siglo, la Zona Franca de Manaos (ZFM) ha sido objeto de relativamente pocos análisis de sus impactos económicos y sociales. El objetivo de este trabajo es presentar una revisión sistemática de las principales estadísticas y de los principales resultados de trabajos seleccionados sobre el tema. Buscamos identificar trabajos que van más allá de la descripción de la evolución de las variables mediante, por ejemplo, el uso de contrafácticos, regresiones econométricas o modelos de equilibrio general. Además, presentamos una breve revisión de la literatura sobre las zonas económicas especiales (ZEE). Los resultados indican que i) la ZFM tiene impactos positivos en los niveles de ingresos y bienestar en Manaos, aunque esta conclusión no es unánime; ii) no hay evidencia concluyente de que la ZFM contribuya a la preservación ambiental de la Amazonía; iii) los gastos federales de impuestos dirigidos a la ZFM se estiman en BRL 28,7 mil millones (más de BRL 380 mil por empleo directo generado); y iv) aunque el enfoque de las ZEE recae, en general, en las exportaciones, el caso de la ZFM es en gran medida único debido a su enfoque en el mercado interno. La ZFM es, por lo tanto, desde un punto de vista legal y desde un punto de vista práctico, esencialmente una política de desarrollo regional (y no una política de incentivos a la exportación) y los análisis sobre el tema deben basarse en esta premisa.

Palabras clave: Zona Franca de Manaos; Zonas Económicas Especiales; Impactos; Gastos de Impuestos; Políticas de Desarrollo Regional.

\section{INTRODUÇÃO}

Criada há mais de meio século, a Zona Franca de Manaus (ZFM) é a principal zona econômica especial (ZEE) existente no Brasil e está explicitamente mencionada na Constituição Federal, que prevê sua manutenção "com suas características de área livre de comércio, de exportação e importação, e de incentivos fiscais" até 2073 (BRASIL, 2019). Situado no coração da Amazônia, o Polo Industrial de Manaus (PIM), que representa a principal face da ZFM, concentra-se nos segmentos de eletroeletrônicos, de bens de informática, de veículos de duas rodas e químico. As dimensões política e econômica dessas iniciativas acabam mobilizando interesses não só dos estados da região Norte, mas também de outras unidades da federação que buscam atrair investimentos. Os números associados à ZFM - discutidos adiante neste trabalho - são significativos, seja quando se consideram seus benefícios, seja quando se consideram seus custos. Contudo, embora exista há mais de 50 anos e mobilize recursos não desprezíveis, a ZFM tem sido objeto de um número relativamente escasso de análises de seus impactos econômicos e sociais. Talvez por essa razão, a ZFM seja um tema que frequentemente desperta reações emocionais. 
As dificuldades para avaliar os impactos das ZEE não são exclusivas do Brasil. Vários organismos internacionais, por exemplo, têm buscado definir procedimentos para avaliar esse tipo de iniciativa (e para identificar as razões para seu eventual sucesso ou fracasso). Esse é o caso, por exemplo, do Banco Mundial (FIAS, 2008; FAROLE; AKINCI, 2011) e da Conferência das Nações Unidas sobre Comércio e Desenvolvimento (UNCTAD, 2019), que publicaram relatórios extensos sobre o tema. Da mesma maneira, diversos acadêmicos têm se debruçado sobre a questão. Moberg (2015), por exemplo, abordou a economia política (isto é, os múltiplos interesses envolvidos) nas ZEE, ao passo que Farole e Moberg (2017) discutiram o caso dos países africanos. Em todos os casos, as análises têm um caráter ad hoc, especialmente porque - conforme se evidencia adiante neste trabalho - as ZEE podem assumir múltiplos formatos cujos impactos podem ser bastante diversos.

O objetivo deste artigo é apresentar uma revisão sistemática das principais estatísticas e dos principais resultados de trabalhos selecionados sobre a ZFM e, em particular, sobre o PIM. Pretende-se, desse modo, amparar o aprofundamento das discussões sobre os custos e os benefícios de iniciativas dessa natureza, não somente visando ao aperfeiçoamento das políticas dirigidas à ZFM, mas também a outras ZEE eventualmente semelhantes no Brasil. O trabalho está segmentado em mais quatro seções além desta introdução. Uma breve discussão sobre o conceito de ZEE, seus múltiplos formatos e impactos é inicialmente apresentada. Essa seção inclui também uma breve descrição das ZEE atualmente existentes no Brasil. Os aspectos de natureza metodológica são tratados na seção seguinte. Os impactos da ZFM são o objeto da penúltima seção, em que aspectos como geração de renda, geração de empregos, proteção ambiental e custos fiscais são discutidos. Finalmente, na última seção, apresentam-se as considerações finais do trabalho.

\section{ZONAS ECONÔMICAS ESPECIAIS}

\section{Definições e tipologia}

Não parece haver uma definição universalmente aceita de ZEE. Com efeito, há vários tipos de iniciativas diversas que podem ser genericamente chamadas desse modo. Nos termos de Farole e Akinci (2011):

Ask three people to describe a special economic zone (SEZ) and three very different images may emerge. The first person may describe a fenced-in industrial estate in a developing country, populated by footloose multinational corporations (MNCs) enjoying tax breaks, with laborers in garment factories 
working in substandard conditions. In contrast, the second person may recount the "miracle of Shenzhen", a fishing village transformed into a cosmopolitan city of 14 million, with per capita gross domestic product (GDP) growing 100fold, in the 30 years since it was designated as an SEZ. A third person may think about places like Dubai or Singapore, whose ports serve as the basis for wide range of trade- and logistics-oriented activities (FAROLE; AKINCI, 2011, p. 1).

Trata-se, de fato, de modelos muito diferentes: distritos industriais formados por maquiladoras são essencialmente distintos do "milagre de Shenzhen"; nenhum desses casos assemelha-se a Dubai ou a Singapura. Contudo, em que pese a distância que separa essas iniciativas umas das outras, todas elas podem ser genericamente classificadas como "zonas econômicas especiais".

Uma definição mais geral e capaz de abranger esse conjunto de iniciativas admite que as ZEE correspondem a áreas geográficas demarcadas nas quais as regras de negócios são diferentes daquelas que prevalecem nas demais regiões do país em que são implantadas. ${ }^{1}$ As regras diferenciadas envolvem principalmente condições de investimento, comércio exterior e alfândega, tributação e ambiente regulatório (LANNES JUNIOR, 2015). Como assinala Moberg (2015), empresas nas ZEE "usually enjoy benefits such as lower tariffs and taxes" e muitas dessas zonas "also offer lower environmental requirements, looser labor regulations, and other policies that lower the cost of doing business" (MOBERG, 2015, p. 170).

De modo geral, o objetivo declarado da implantação de ZEE é usá-las como instrumentos de políticas comerciais, de investimento e regionais (FAROLE; MOBERG 2017). A ênfase relativa em cada um desses três aspectos, contudo, varia muito. No caso do Brasil, conforme se argumenta na próxima seção deste trabalho, as ZEE são, de modo geral, instrumentos de política de desenvolvimento regional. O “milagre de Shenzhen”, por outro lado, é basicamente dirigido para o mercado externo.

Sob o amplo guarda-chuva da definição geral de ZEE, há um grande número de categorias. A tipologia usada pela FIAS (2008), por exemplo, considera seis diferentes modalidades de ZEE. Essa tipologia e os ajustes propostos por Farole (2011) foram resumidos por Lannes Júnior (2015) na tabela abaixo:

\footnotetext{
1 A exceção, nesse caso, é Singapura, que é uma cidade-estado.
} 
| Luiz Ricardo Cavalcante |

Tabela 1 - Modalidades de ZEE

\begin{tabular}{|c|c|c|c|c|c|}
\hline Modalidade & Objetivo & Extensão & Localização & Atividades & Mercados \\
\hline $\begin{array}{l}\text { Zonas de livre } \\
\text { comércio }\end{array}$ & Comércio & $<50$ ha & $\begin{array}{l}\text { Porto de } \\
\text { entrada }\end{array}$ & $\begin{array}{l}\text { Entreposta- } \\
\text { mento / comércio }\end{array}$ & $\begin{array}{l}\text { Doméstico / } \\
\text { reexportação }\end{array}$ \\
\hline $\begin{array}{l}\text { Zonas de } \\
\text { processamento de }\end{array}$ & $\begin{array}{l}\text { Exportações } \\
\text { industriais }\end{array}$ & $<100$ ha & & $\begin{array}{c}\text { Industrialização / } \\
\text { outros }\end{array}$ & $\begin{array}{c}\text { Majoritariamente } \\
\text { externo }\end{array}$ \\
\hline Zonas empresariais & $\begin{array}{l}\text { Recuperação de } \\
\text { áreas degradadas }\end{array}$ & & Cidade & Comércio /lazer & Local \\
\hline Portos livres & $\begin{array}{l}\text { Urbanização } \\
\text { integrada }\end{array}$ & $\begin{array}{c}<1.000 \\
\text { ha }\end{array}$ & & Multiuso & $\begin{array}{c}\text { Doméstico / } \\
\text { externo }\end{array}$ \\
\hline $\begin{array}{l}\text { ZPE de } \\
\text { estabelecimento }\end{array}$ & $\begin{array}{l}\text { Exportações } \\
\text { industriais }\end{array}$ & & & $\begin{array}{c}\text { Industrialização / } \\
\text { Outros }\end{array}$ & $\begin{array}{c}\text { Majoritariamente } \\
\text { externo }\end{array}$ \\
\hline $\begin{array}{l}\text { Zonas } \\
\text { especializadas }\end{array}$ & $\begin{array}{c}\text { Polo de } \\
\text { desenvolvimento }\end{array}$ & & & $\begin{array}{c}\text { Industrialização / } \\
\text { tecnologia }\end{array}$ & $\begin{array}{c}\text { Doméstico / } \\
\text { externo }\end{array}$ \\
\hline
\end{tabular}

Fonte: Lannes Junior (2015), com base em FIAS (2008) e em Farole (2011).

Naturalmente, é possível propor outras tipologias (ver, por exemplo, UNCTAD, 2019). Contudo, as modalidades resumidas na tabela acima parecem suficientemente abrangentes e capazes de dialogar com as iniciativas existentes no Brasil e com a ZFM, em particular.

\section{Impactos das ZEE}

A multiplicidade de formatos que as ZEE podem assumir impede uma avaliação sistemática de seus impactos econômicos e sociais. De fato, são escassas as possibilidades de análises estatísticas de impactos, uma vez que não há como acomodar, em uma mesma série de dados, as múltiplas espécies mencionadas acima. Mesmo que isso fosse possível, as dificuldades inerentes a esse tipo de avaliação (por exemplo, quanto ao horizonte temporal dos impactos ou ao grande número de premissas ad hoc que geralmente têm que ser feitas) colocam obstáculos adicionais para estudos amparados em regressões econométricas.

Por essa razão, as análises de impactos das ZEE tendem a apresentar um caráter mais "anedótico", prevalecendo estudos de caso (sobre um único ou sobre vários deles) ou revisões sistemáticas de estudos de caso. Além disso, são usualmente precedidas por um esforço de delimitação do objeto e da abrangência geográfica do trabalho. Desse modo, Amirahmadi e Wu (1995) e Jayanthakumaran (2003) analisam especificamente as ZPE na Ásia; Farole (2011) e Farole e Moberg (2017) tratam das ZEE na África e Joshi e Narkhede (2008) discutem as ZEE na Índia. ${ }^{2}$

\footnotetext{
${ }^{2}$ Há, porém, alguns poucos trabalhos que têm outro formato. Hausmann, Obach e Santos (2016), ao
} analisarem as ZEE no Panamá, comparam, com base em regressões econométricas, indicadores de firmas 
| Luiz Ricardo Cavalcante |

Muitas análises sobre os impactos das ZEE têm um caráter de certo modo tautológico. Argumenta-se, basicamente, que, quando bem-sucedidas, as ZEE de fato conseguem alcançar os objetivos que orientaram sua criação: aumentar os níveis de competitividade, atrair investimentos e promover o crescimento econômico (FAROLE; MOBERG, 2017). Não bastaria, contudo, constatar que as ZEE que obtiveram sucesso geram impactos positivos (até porque isso é evidente); seria preciso confrontar esses impactos com os custos em que se incorreu para gerá-los. Além disso, de algum modo, o sucesso das ZEE não é uma variável binária, mas contínua (isto é, há diferentes graus de sucesso e, portanto, os impactos são também escalonados). Hausmann, Obach e Santos (2016) apontam a existência de benefícios estáticos (atração de investimentos, geração e empregos e ganhos de produtividade) e de benefícios das ZEE em seu entorno (“beyond their boundaries"). Esses benefícios envolvem spillovers tecnológicos e a difusão de conhecimentos. De qualquer modo, o sucesso das ZEE está condicionado à presença de um conjunto de pré-requisitos. Gebrewolde (2019), por exemplo, aponta os seguintes fatores: políticas coordenadas, oferta de mão de obra barata, infraestrutura, logística comercial e aquilo que chama de "facilitation systems". Isso sugere que instituições "externas" à ZEE (i.e., instituições nacionais) e uma série de outros fatores "idiossincráticos" podem concorrer para seu sucesso. Essas análises deixam claro que há casos (marcados pela ausência desses fatores) em que as ZEE não geram os resultados esperados.

\section{ZEE no Brasil}

As ZEE formalmente estabelecidas no Brasil envolvem a ZFM, as áreas de livre comércio (ALC) e as ZPE. Nesse conjunto, destaca-se, por sua magnitude, a ZFM, que tem o maior estoque de investimentos e que mobiliza os maiores níveis de benefícios fiscais das ZEE existentes no país. Trata-se de um modelo que não se enquadra precisamente em nenhuma das modalidades indicadas na tabela 1. Com efeito, não se trata apenas de uma “zona de livre comércio" porque seu foco é a industrialização. Por outro lado, a ênfase no mercado interno descarta seu enquadramento como ZPE. Tampouco se enquadra nas demais categorias indicadas. Trata-se, na prática, de uma espécie de zona de livre comércio destinada à industrialização com foco no mercado interno, conforme se discute na próxima seção.

Na Região Amazônica, há ainda as ALC, criadas, de acordo com a Superintendência da Zona Franca de Manaus (Suframa), "para promover o desenvolvimento das cidades de 
fronteiras internacionais localizadas na Amazônia Ocidental e em Macapá e Santana, com o intuito de integrá-las ao restante do país, oferecendo benefícios fiscais semelhantes aos da Zona Franca de Manaus no aspecto comercial". ${ }^{3}$ Nesse caso, portanto, seu enquadramento como "zona de livre comércio" conforme indicado na tabela 1 parece razoável.

A terceira espécie de ZEE formalmente instituídas no Brasil corresponde às ZPE, que se caracterizam "como áreas de livre comércio com o exterior, destinadas à instalação de empresas voltadas para a produção de bens a serem comercializados no exterior". ${ }^{4}$ De acordo com o site do Ministério da Economia, o Brasil possui 16 ZPE autorizadas que se encontram em efetiva implantação. ${ }^{5}$ Nesse conjunto, somente a ZPE de Pecém (CE) conta com empresas industriais já em funcionamento. ${ }^{6}$ As exigências legais de foco no mercado externo e o volume proporcionalmente menor de incentivos fiscais nas ZPE possivelmente explicam porque várias delas, embora formalmente instituídas, não estão efetivamente em atividade. Por outro lado, a remoção dessas exigências tenderia a converter as ZPE simplesmente em distritos industriais incentivados (sem o correspondente foco no comércio exterior).

\section{ASPECTOS METODOLÓGICOS}

Do ponto de vista metodológico, empregou-se, para a elaboração deste trabalho, aquilo que se poderia chamar de "revisão bibliográfica", de "metanálise" ou de "revisão sistemática”. Essas expressões pressupõem a seleção de um certo número de referências e o cruzamento de seus resultados visando a identificar seus pontos de convergência e de dissonância. Cada uma dessas expressões envolve uma discussão metodológica muitas vezes detalhada. Por exemplo, a expressão "metanálise" pressupõe, em geral, a integração de resultados de trabalhos independentes e é mais frequentemente usada quando os resultados são consolidados com base em algum tipo de tratamento estatístico. Por essa razão, preferiu-se utilizar a expressão "revisão sistemática", considerando seu caráter mais geral. Nos termos de Souza e Ribeiro (2009), trata-se de uma revisão da literatura científica

\footnotetext{
${ }^{3}$ Disponível em https://cutt.ly/7iX2ZQB. Acesso em 29 jun. 2020.

${ }^{4}$ Disponível em https://cutt.ly/xiX9ebO. Acesso em 29 jun. 2020.

5 ZPE do Acre (AC), ZPE do Açú (RJ), ZPE de Araguaína (TO), ZPE de Barcarena (PA), ZPE de Bataguassú (MS), ZPE de Boa Vista (RR), ZPE de Cáceres (MT), ZPE de Fernandópolis (SP), ZPE de Ilhéus (BA), ZPE de Imbituba (SC), ZPE de Macaíba (RN), ZPE de Parnaíba (PI), ZPE de Pecém (CE), ZPE de Suape (PE), ZPE de Teófilo Otoni (MG) e ZPE de Uberaba (MG). Disponível em https://cutt.ly/OyFsZz4. Acesso em 28 de maio de 2020.

${ }^{6}$ Nesse caso, os investimentos estimados alcançam US\$ 5,7 bilhões (disponível em https://cutt.ly/6taCbjC. Acesso em 11 mar. 2020).
} 
com base em "systematic methods to identify, select and critically analyze relevant studies on a clearly formulated question" (SOUZA; RIBEIRO, 2009, p. 229). Embora essa expressão seja mais amplamente usada na área de saúde, ${ }^{7}$ sua descrição não parece divergir daquilo que se pretendeu fazer neste trabalho, razão pela qual optou-se por descrevê-lo, do ponto de vista da metodologia aplicada, como uma revisão sistemática.

Buscou-se, em particular, identificar os trabalhos mais influentes publicados sobre a ZFM ao longo das décadas de 2000 e de 2010. A seleção desses trabalhos tende a ser razoavelmente consensual entre aqueles que estudam o tema, haja vista sua presença recorrente, em vários casos, nas referências bibliográficas de artigos técnicos e acadêmicos, de dissertações de mestrado de teses de doutorado. A ferramenta "Google Scholar" foi usada de forma complementar para identificar outros trabalhos eventualmente ausentes do padrão usual de citações. A opção por essa base de dados decorre de sua capacidade de identificar não somente trabalhos estritamente acadêmicos, mas também documentos de caráter técnico envolvendo, por exemplo, relatórios publicados por organizamos multilaterais ou órgãos do governo brasileiro. ${ }^{8}$ Buscou-se, contudo, evitar a inclusão de trabalhos explicitamente voltados para a defesa de interesses específicos. Apesar desses procedimentos, sempre poderá haver questionamentos sobre a inclusão ou não de um determinado trabalho nas referências de qualquer análise desse tipo, inclusive porque sempre haverá algum nível de subjetividade nas escolhas. Espera-se, contudo, que mesmo esse tipo de discussão possa contribuir para o alargamento das análises sobre os impactos da ZFM.

De qualquer modo, a produção bibliográfica (ou mesmo técnica) em que se avaliam os impactos da ZFM é escassa e dispersa. A maioria dos trabalhos sobre o tema contém análises essencialmente descritivas (das estatísticas ou da história da ZFM) ou simplesmente atribui a evolução de uma certa variável à presença da ZFM, sem buscar identificar relações de causalidade ou considerar o efeito de outros fatores. ${ }^{9}$ Trata-se de um procedimento que poderia ser descrito como "correlação coincidente" ou "post hoc ergo propter hoc" ("depois disso, logo por causa disso").

As publicações em que se usa algum tipo de técnica estatística ou econométrica são ainda mais raras. Ainda assim, foram identificados trabalhos em que se usam contrafactuais,

\footnotetext{
${ }^{7}$ Baena (2014) assinala que a reunião de evidência sumarizada com precisão e poder de análise tem sido recurso cada vez mais importante no setor de saúde. Várias análises desse tipo têm sido usadas, por exemplo, para avaliar o uso de medicamentos no tratamento da Covid-19.

${ }^{8}$ Ver, a respeito do uso do Google Scholar em pesquisas na área de ciências humanas, Prins et al. (2016).

${ }^{9}$ Ver, por exemplo, Oliveira e Souza (2012) ou Marchioro, Gubert e Gubert (2014).
} 
regressões econométricas ou modelos de equilíbrio geral, por exemplo, para avaliar os impactos da ZFM. Esses trabalhos são discutidos na seção subsequente.

Por fim, em muitos casos, é preciso especificar a abrangência regional dos impactos (Manaus, região metropolitana de Manaus, estado do Amazonas ou região Norte, por exemplo). No caso dos custos fiscais, o foco da análise recai, majoritariamente, sobre o Brasil, uma vez que a maior parte das renúncias se dá no nível dos tributos federais. Da mesma forma, a análise da balança comercial considera o país como um todo. Por outro lado, os empregos gerados ou os impactos no produto interno bruto (PIB) são usualmente confrontados com indicadores locais.

\section{IMPACTOS DA ZFM: principais estatísticas e revisão sistemática}

A história da ZFM remonta ao início da década de 1950, quando o Projeto de Lei (PL) 1.310/1951 propôs a criação de um "porto franco" em decorrência “das dificuldades geográficas do meio e da solidariedade continental que tem sido a linha dominante da nossa política internacional". ${ }^{10}$ A lei resultante (Lei 3.173/1957) já faz referência a uma zona franca "para armazenamento ou depósito, guarda, conservação, beneficiamento e retirada de mercadorias, artigos e produtos de qualquer natureza, provenientes do estrangeiro e destinados ao consumo interno da Amazônia, como dos países interessados, limítrofes do Brasil ou que sejam banhados por águas tributárias do rio Amazonas". ${ }^{11}$

Dez anos depois, o modelo foi reformulado pelo Decreto-Lei 288/1967, e foram instituídos incentivos fiscais "com a finalidade de criar no interior da Amazônia um centro industrial, comercial e agropecuário dotado de condições econômicas que permitam seu desenvolvimento, em face dos fatores locais e da grande distância, a que se encontram, os centros consumidores de seus produtos". ${ }^{12}$ De forma mais ou menos explícita, essa parece ser, essencialmente, a definição mais amplamente aceita da ZFM: um espaço delimitado no qual vigoram incentivos fiscais especiais capazes de compensar as desvantagens locacionais da região ("fatores locais" e distância dos centros consumidores) e, desse modo, promover seu desenvolvimento econômico (explicitamente) e social e ambiental (nesse dois casos, de maneira apenas implícita).

A Constituição Federal de 1988, no art. 40 do Ato das Disposições Constitucionais Transitórias (ADCT), manteve a ZFM “com suas características de área livre de comércio,

\footnotetext{
${ }^{10}$ Disponível em: https://cutt.ly/yybDYa9 . Acesso em: 11 maio 2020.

${ }^{11}$ Disponível em: https://cutt.ly/NybD93Q. Acesso em: 11 maio 2020.

12 Disponível em: https://cutt.ly/SybFeuF. Acesso em: 11 maio 2020. Ver também Miranda (2013).
} 
de exportação e importação, e de incentivos fiscais, pelo prazo de vinte e cinco anos, a partir da promulgação da Constituição". Mais tarde, o art. 92 do ADCT, incluído pela Emenda Constitucional (EC) 42/2003, estendeu o prazo de vigência fixado no art. 40 do ADCT por mais dez anos. Pouco mais de dez anos depois, o Congresso Nacional promulgou a EC 83/2014, que, na prática, prorrogou os benefícios tributários destinados à ZFM até 2073 (REY; CARDOSO JÚNIOR, 2019).

A legislação relativa à ZFM de certo modo indica as principais dimensões a serem consideradas nas avaliações de seus impactos: de um lado, indicadores de desenvolvimento econômico, social e ambiental; de outro, indicadores de custos fiscais associados às renúncias tributárias previstas em lei. No caso específico da ZFM, indicadores demográficos são também às vezes mencionados porque a ocupação da Amazônia foi um dos objetivos usados para justificar a iniciativa. ${ }^{13}$ Busca-se, nesta seção, organizar as informações sobre os impactos relacionados à população, ao PIB, ao número de empregos gerados, ao meio ambiente e aos custos fiscais da ZFM. Analisa-se ainda o comportamento da balança comercial da ZFM porque as exportações são, conforme se evidenciou na segunda seção deste trabalho, um dos principais objetivos das ZEE implantadas em outros países.

Vários trabalhos mencionados nesta seção usam contrafactuais, regressões econométricas ou modelos de equilíbrio geral. Em alguns casos, as análises não se limitam a uma única variável (por exemplo, ao PIB per capita) e tratam de múltiplas dimensões. Esse é o caso de Miranda (2013), que discute os desafios e as vulnerabilidades da ZFM, ou de Holland (2019), que, em uma extensa publicação intitulada "Zona Franca de Manaus: impactos, efetividade e oportunidades", trata de múltiplos aspectos relativos ao tema. ${ }^{14} \mathrm{Em}$ vários desses casos, os trabalhos são extensos e multidimensionais, não podendo, por essa razão, ser resumidos neste artigo. Nesses casos, enfatizam-se aos aspectos considerados mais controversos ou mais originais de cada um deles.

\section{População}

Não é usual que políticas de desenvolvimento econômico usem medidas de crescimento populacional como indicadores de sucesso. De modo geral, busca-se elevar os indicadores per capita como, por exemplo, o PIB per capita ou o índice de desenvolvimento

\footnotetext{
${ }^{13}$ A exposição de motivos do Decreto-Lei 288/1967 menciona explicitamente que "as facilidades concedidas pelos governos estrangeiros em outras áreas limítrofes à Amazônia brasileira trouxeram um profundo surto de desenvolvimento e consequentemente êxodo de novas populações fronteiriças para esses países" (Exposição de motivos 21/1967 apud CRUZ, 2009). Ver também, a esse respeito, Seráfico e Seráfico (2005). $14 \mathrm{O}$ trabalho não tem data, mas infere-se que tenha sido publicado no final de 2018 ou em 2019.
} 
humano (IDH). No caso da ZFM, porém, pelas razões mencionadas acima, os indicadores demográficos são usados por alguns autores.

Não foram identificados estudos em que se usem métodos mais elaborados para a análise dos impactos da ZFM na população local. Os trabalhos que tratam desse tema, de modo geral, descrevem a evolução dessa variável e eventualmente a confrontam com a evolução da população do Brasil ou de outras regiões do país. Marchioro, Gubert e Gubert (2014), por exemplo, registram que “a implantação do projeto da ZFM foi responsável por um acréscimo de 194,5\% na população do estado do Amazonas entre os anos de 1970 a 2000, o que corresponde a uma média anual de 3,7\%, considerada elevada, pois o Brasil apresentou crescimento da população no mesmo período em termos de $2 \%$ " (MARCHIORO; GUBERT; GUBERT, 2014, p. 196). Entretanto, diversas outras regiões, no mesmo período, podem ter exibido taxas de crescimento superiores à média nacional. Além disso, esse tipo de análise simplesmente despreza outras iniciativas que podem, eventualmente, ter contribuído para a trajetória das variáveis analisadas (como a expansão do agronegócio ou do turismo, por exemplo).

De qualquer modo, o período posterior à implantação da ZFM coincidiu com uma expansão da população na região Norte mais acelerada do que a expansão média do país. Nesse sentido, a "ocupação da Amazônia" teria de fato ocorrido. Contudo, Araújo (2009) argumenta que a urbanização, a industrialização e o crescimento do setor terciário aumentaram a demanda por serviços públicos e por infraestrutura urbana, colocando novos desafios para os formuladores de políticas.

\section{PIB e empregos gerados}

De acordo com estatísticas publicadas pela Suframa, havia, em setembro de 2019, um total de 436 empresas no PIM responsáveis pela geração de 73 mil empregos diretos. Os dados de faturamento relativos a 2014 (não foram localizados dados referentes a 2019) apontam para um total de $\mathrm{R} \$ 87$ bilhões; em dezembro daquele ano, o número de empresas havia chegado a 492 e o total de empregos diretos gerados era da ordem de 110 mil. Embora obviamente associados à geração de renda pela ZFM (ou pelo PIM, em particular), esses dados não correspondem a uma medida direta da geração de renda, uma vez que não há indicadores imediatos da agregação local de valor.

A agregação de valor na ZFM foi objeto do trabalho de Bispo (2009). Esse autor usou dados das empresas que publicaram demonstrações de valor adicionado entre 2003 e 2007 e concluiu que as empresas industriais instaladas na ZFM criam, em média, 30,96\% de riqueza em função do faturamento, enquanto as empresas semelhantes situadas fora dessa 
região geram, em média, 45,08\%. Estimativas com base em regressões lineares levam a uma diferença ainda maior: (31,07\% contra 54,36\%). Bispo (2009) utiliza dados contábeis e considera o impacto dos incentivos fiscais em suas estimativas.

Sá e Machado (2012), usando dados da Pesquisa Industrial Anual (PIA) relativos ao período entre 1996 e 2010, chegam a uma conclusão oposta. Esses autores concluem que a relação entre valor da transformação industrial (VTI) e o valor bruto da produção industrial (VBPI) da indústria de transformação no Amazonas superou essa relação para o país como um todo em vários anos. Entre 2006 e 2010, o valor calculado para o Amazonas superou sistematicamente o do Brasil e, em 2010 (último ano da série analisada por aqueles autores), a relação VTI/VBTI da indústria de transformação do Amazonas alcançou 45,4\%, ao passo que, no caso do país como um todo, a relação foi de 43,2\%. Em sua análise, Sá e Machado (2012) essencialmente assumem que a indústria de transformação do Amazonas corresponderia à ZFM. Com base nas premissas adotadas e nos resultados obtidos, os autores contestam o argumento de que a ZFM seria formada por "maquiladoras". Isso ampara sua proposição de que seria preciso prorrogar a ZFM, ainda que aperfeiçoando o modelo adotado.

Os trabalhos de Bispo (2009) e de Sá e Machado (2012) empregam métodos e bases de dados diferentes e tratam de intervalos distintos. A rigor, Sá e Machado (2012) sequer analisam a ZFM, mas a indústria de transformação do Amazonas. De qualquer modo, os resultados divergentes sugerem que não há uma conclusão consagrada sobre a relação entre a agregação de valor na ZFM e no Brasil. Contudo, é improvável que as empresas na ZFM tenham sido, ao longo de décadas, menos rentáveis do que empresas semelhantes em outras partes do país (considerando, é claro, os incentivos a que têm acesso).

É razoável assumir que os incentivos fiscais se prestam, justamente, a algum tipo de equalização (tal como se mencionava quando a ZFM foi criada). O ponto central, nesse caso, seria sua calibração. Incentivos muito baixos podem não ser capazes de compensar as desvantagens locacionais e de provocar um movimento dos investimentos em direção à região na qual se pretende intervir; incentivos muito elevados, por outro lado, podem gerar custos tributários elevados e levar a uma canibalização dos investimentos nas demais regiões. $\mathrm{Na}$ prática, porém, as reduções de alíquotas aplicadas à ZFM são rígidas e eventuais compensações acabam resultando da concessão de novos incentivos destinados a outras regiões ou ao restante do país. Esse é o caso da Lei 8.248/1991 ("Lei de Informática"), que, conforme argumenta Souza (2011), acaba funcionando como uma espécie de compensação para as empresas situadas fora da ZFM. 
O gráfico 1 registra a evolução do número de empregos diretos gerados pelas empresas instaladas no PIM entre janeiro de 2010 e setembro de 2019.

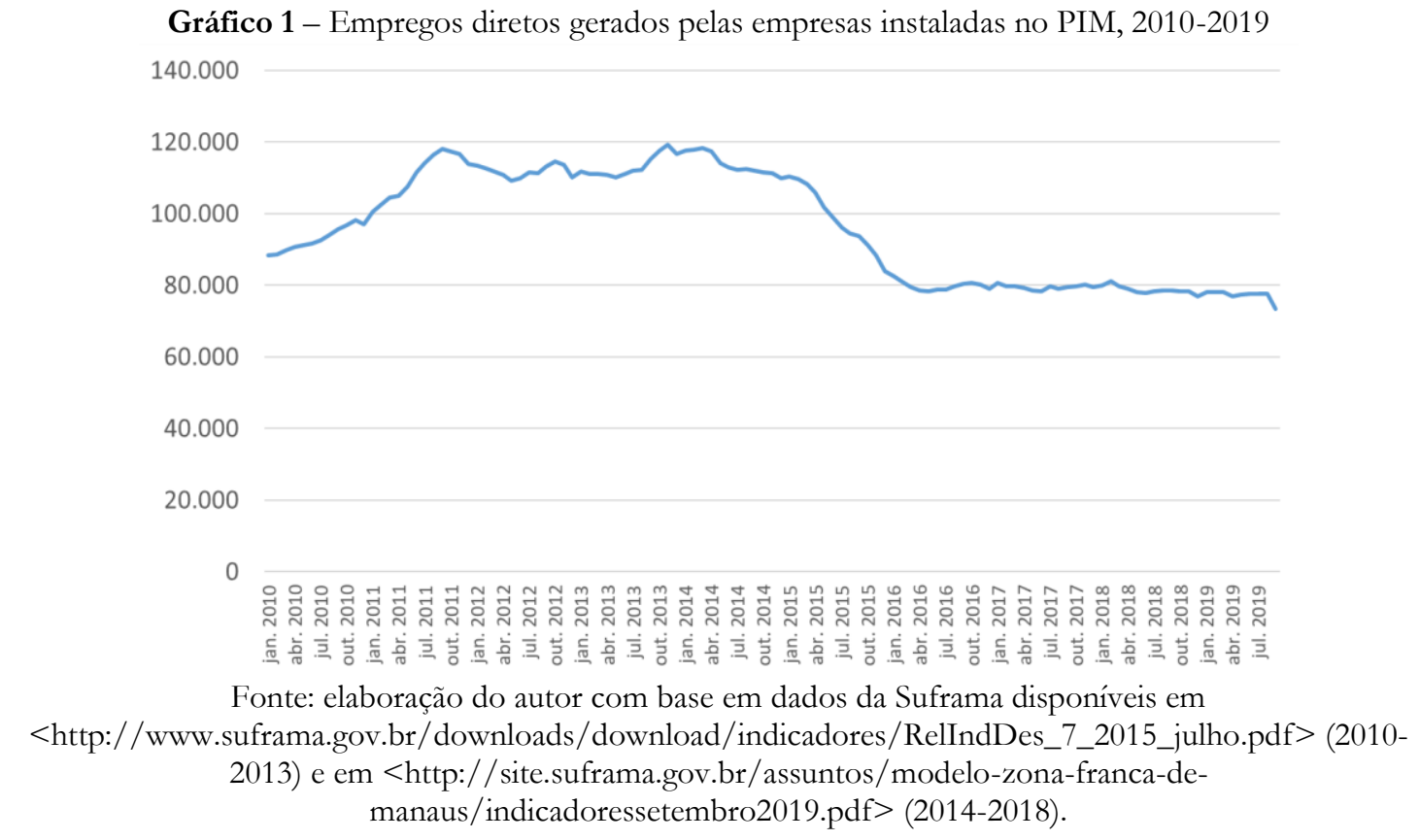

De maneira consistente com a evolução do número de empresas, o gráfico mostra que os empregos diretos gerados no PIM caíram de quase 120 mil, em meados da década de 2010, para menos de 75 mil, no final do período analisado. Trata-se de um valor inferior àquele que se observava em 2010. Ainda assim, os números mais recentes não são pequenos e correspondem a cerca de 3,5\% da população de Manaus (cerca de 2,2 milhões de pessoas).

Andrade, Gelcer e Holland (2019) consideram um multiplicador do emprego da ordem de 4:1, de modo que quatro empregos indiretos seriam gerados para cada emprego direto. Assim, o número total de pessoas empregadas em função da ZFM alcançaria mais de 350 mil em 2019, ou de 500 mil no trabalho de Andrade, Gelcer e Holland (2019), que consideram a geração de 100 mil empregos diretos. Há, aqui, contudo, dois problemas de ordem metodológica que apontam que esse número deve ser usado com muita cautela:

- Não há indicadores claros ou conclusivos da relação 4:1 para as empresas instaladas no PIM.

- Os empregos indiretos que efetivamente existem ao longo da cadeia produtiva (independentemente de seu total) dificilmente seriam gerados nos arredores da ZFM. A tendência seria que os fornecedores eventualmente instalados na região 
estivessem dentro da própria ZFM (e, portanto, já contabilizados nas estatísticas da Suframa) para usufruir dos benefícios fiscais em vigor. ${ }^{15}$

De qualquer modo, é evidente que a geração de cerca de 75 mil empregos diretos no setor industrial (ou quase $120 \mathrm{mil}$, se considerado o período recente) gera renda do trabalho em Manaus, com repercussões em seus indicadores econômicos e sociais. Entretanto, em poucas ocasiões esse número é confrontado com os custos incorridos (especialmente em termos de renúncias tributárias) para gerá-lo.

Miranda (2013), ao discutir a viabilidade da ZFM, avalia seus custos fiscais e sua capacidade de gerar empregos. $\mathrm{O}$ autor argumenta que os salários médios na ZFM são inferiores aos salários médios no setor de construção civil no Amazonas, escolhido "por ser reconhecido como empregador de pessoas pouco qualificadas profissionalmente e por pagar baixos salários" (MIRANDA, 2013, p. 13). O autor pondera ainda que a ZFM teria impactos negativos na concentração de renda com base, inclusive, na estimativa das transferências de recursos de estados e municípios brasileiros para a ZFM decorrentes das isenções do imposto sobre produtos industrializados (IPI) e da consequente redução do volume de recursos destinados ao fundo de participação dos estados (FPE) e ao fundo de participação dos municípios (FPM).

Com relação a esse tema, há ainda alguns trabalhos que, embora não discutindo a capacidade da ZFM gerar empregos ou seu custo associado, tratam dos níveis salariais e das condições de trabalho nas indústrias (SCHERER, 2004; SILVA, 2004; BRITO; MACIEL, 2019). Da mesma forma, Araújo (2009) argumenta que "os níveis salariais não são elevados, além de existir uma importante rotatividade nas empresas" (ARAÚJO, 2009, p. 41).

Possebom (2017) utiliza o método do controle sintético para dados dos municípios da região Norte para estimar o efeito causal da ZFM no PIB per capita e na produção agrícola, industrial e de serviços per capita. ${ }^{16}$ O autor usa dados relativos aos anos de 1920, 1939, 1949, 1959, 1970, 1975, 1980, 1985, 1996 e 1999 (1920 - 1959 corresponde ao período de "pré-tratamento"). A partir desses dados, conclui que houve impactos positivos no PIB per capita e na produção de serviços per capita, impactos negativos na produção agrícola per capita e que não houve impacto na produção industrial per capita. Esse último resultado é contraintuitivo em face da relevância da indústria no PIM. O impacto no setor

\footnotetext{
15 A exceção seriam os serviços non-tradable que, por definição, tenderiam a se localizar em Manaus. Nesse caso, porém, a julgar pelo número de terceirizados registrado pela Suframa (da ordem de 10 mil em setembro de 2019), os empregos indiretos gerados na região e não contabilizados nas estatísticas divulgadas tende a ser reduzido.

${ }^{16}$ Nos termos de Possebom (2017): "intuitively, the synthetic control method constructs a synthetic control unit based on a weighted average of control regions that is as similar as possible to the treated region in terms of covariates and pre-treatment outcomes" (POSSEBOM, 2017, p. 218).
} 
de serviços, de acordo com Possebom (2017), "indicates that the main impact of the FTZM was due to lower import tariffs than those imposed in the rest of the country, attracting Brazilian tourists willing to buy imported goods at lower prices". O resultado global (impacto positivo no PIB per capita), por sua vez, parece intuitivo: é esperado que um município que recebeu incentivos federais e estaduais significativos tenha desempenho superior a outros municípios semelhantes que não tiveram acesso a esses benefícios.

De maneira convergente, Holland e Pieri (2019) afirmam que "é marcante a evolução do PIB per capita na região pesquisada, tanto em comparação com estados vizinhos, quanto com estados mais industrializados". Essa conclusão ampara-se em comparações diretas e não leva em conta o papel de outras variáveis que afetam a renda per capita. Quando fazem uso do controle sintético, Pieri, Albuquerque e Cerqueira (2019) observam "diversos efeitos positivos [...], mas também alguns efeitos neutros e outros mesmo que positivos ou negativos não estatisticamente significativos".

Por outro lado, Gonçalves (2018) utiliza uma estimação de diferenças-emdiferenças (“DiD”) no período entre 2002 e 2014 e constata que os gastos tributários não aumentaram o valor adicionado bruto (VAB), o PIB, a renda ou os impostos no Amazonas (isto é, apresentaram crescimento menor que a média brasileira e a média da região Norte). ${ }^{17}$ Por outro lado, aponta efeitos positivos na população e no emprego de trabalhadores com níveis mais baixos de escolaridade. Esses resultados o levam a apontar as fragilidades e as limitações da ZFM como indutora do crescimento e do desenvolvimento econômico regional. Ao contrário dos trabalhos anteriores, o estudo de Gonçalves (2018) inclui, no modelo adotado, o volume de recursos destinados à ZFM (isto é, os benefícios fiscais que lhe são dirigidos).

\section{Meio ambiente}

Um dos argumentos mais frequentemente evocados para defender a ZFM diz respeito a seus eventuais impactos ambientais positivos. O pressuposto é simples: ao criar oportunidades econômicas em Manaus, a ZFM reduziria a pressão sobre a floresta e o desmatamento. Esse argumento foi evocado, por exemplo, pela então presidente Dilma Rousseff, em 2014, em pronunciamento na União Europeia. Declaração do ministro Paulo Guedes em Davos contrapondo o desmatamento à pobreza, em 2020, pode também amparar uma abordagem dessa natureza. Embora recorrentemente evocado e disseminado

17 Gonçalves (2018) registra que o DiD é utilizado para determinar o impacto de uma política exógena, utilizando dados de antes da implementação dessa política e dados de depois de sua implementação (NERI; MEDRADO, 2017 apud GONÇALVES, 2018). 
em um amplo espectro ideológico, contudo, esse argumento genérico (que, na verdade, seria uma hipótese a ser verificada) foi objeto de uma produção bibliográfica escassa e dispersa.

Destacam-se, neste trabalho, quatro documentos que contêm informações sobre os impactos ambientais da ZFM: i) o documento intitulado "Análise ambiental e de sustentabilidade do estado do Amazonas" (CEPAL, 2007); ii) o livro "Instrumentos econômicos para a proteção da Amazônia" (RIVAS; MOTA; MACHADO, 2009); iii) a dissertação "O Polo Industrial da Zona Franca de Manaus e a preservação da floresta amazônica: caminhos independentes" (COSTA, 2016), e iv) o trabalho de Gurgel e Serigatti (2019) incluído na publicação coordenada por Holland et al. (2019) mencionada anteriormente.

O documento publicado pela Cepal (2007, p. 19) avalia "a biodiversidade, os setores agropecuário, florestal e pesqueiro e a integração do meio ambiente na economia e na área social" e, portanto, não trata do PIM. Ainda assim, o documento indica que "o modelo de desenvolvimento industrial do estado, concentrado na Zona Franca de Manaus [...], tem sido um freio até agora dos processos de degradação ambiental que outros estados amazônicos vêm sofrendo" (CEPAL, 2007, p. 19). Entretanto, conforme destaca Costa (2016), não se apresenta qualquer evidência dessa afirmação.

Uma análise mais detalhada dos impactos ambientais da ZFM é o objeto do livro organizado por Rivas, Mota e Machado (2009). Em particular, o capítulo de Mota e Cândido Jr. (2009) apoia-se em um modelo que segue, em linhas gerais, a seguinte sequência:

- Selecionaram-se quatro municípios em que houve desmatamento e que não sofreriam influência da ZFM.

- O desmatamento nesses municípios foi atribuído a um conjunto de fatores (quantidade de rebanho bovino, área de lavoura e população, por exemplo). Regressões econométricas foram então construídas para relacionar, quantitativamente, as áreas desmatadas à magnitude desses fatores.

- Com base nos resultados das regressões, assumiu-se que Manaus seguiria o padrão dos quatro municípios selecionados e construiu-se uma espécie de contrafactual.

Os autores concluem que "a média do desmatamento evitado em Manaus, de acordo com os modelos estimados, é de 5,2 mil km²" (MOTA; CÂNDIDO JR, 2009, p. 153). Uma vez obtida a redução da área desmatada, os autores estimam o benefício monetário correspondente e obtêm o valor de quase US\$ 400 milhões, majoritariamente 
associados ao estoque de carbono (quase 95\% do total) e à preservação da biodiversidade. Esse valor anual é então multiplicado por 11 anos (isto é, para o período 1997-2007) para se estimar um benefício total da ordem de US\$ 4,4 bilhões (MOTA; CÂNDIDO JR, 2009, p. 155).

O método é criticado por Costa (2016) que, por exemplo, questiona a hipótese de que Manaus estaria submetida às mesmas condições dos quatro municípios selecionados. Argumenta ainda que, ao se calcular o desmatamento em Manaus na ausência do PIM, as estimativas deveriam embutir os movimentos migratórios motivados especificamente pela ZFM. O autor conclui que "não é possível afirmar que as atividades desenvolvidas pelo PIM contribuam para a preservação florestal da cidade de Manaus, ou ainda para qualquer outra região da Amazônia". Além disso, afirma que:

[...] as razões pelas quais o Amazonas é o estado com uma das maiores porcentagens relativas de cobertura florestal preservada [...] estão fundamentadas em sua geografia, suas restritas condições de acesso, nas inúmeras áreas legais de conservação e preservação, nos acordos institucionais com os setores econômicos da carne, soja e madeira, na distância dos mercados consumidores e no seu próprio tamanho, elementos estes que nada têm em comum com o PIM.

Por fim, Gurgel e Serigatti (2019), com base em um modelo de equilíbrio geral computável, encontraram "uma correlação significativa e negativa (-0.056) entre a população ocupada formalmente nas atividades industriais dos municípios da ZFM e o desmatamento no Estado do Amazonas". Os autores alertam que a intensidade dessa relação, contudo, "é bastante modesta" e ressaltam que, de qualquer forma, os resultados são sensíveis a um conjunto de premissas usadas no modelo. Curiosamente, no sumário executivo da mesma publicação, afirma-se que "as consequências socioeconômicas e ambientais de eventual desestruturação do Polo Industrial de Manaus são incalculáveis".

\section{Custos fiscais}

Dados mais recentes estimam as renúncias fiscais associadas à ZFM (e às ALC, que representam apenas uma pequena parte desse total) em R $\$ 28,7$ bilhões em $2020{ }^{18}$ Trata-se de um valor semelhante aos gastos com o programa bolsa família, orçados em $R \$ 29,5$ bilhões também em 2020. ${ }^{19}$ Comparações desse tipo são virtualmente infinitas: pode-se escolher um valor maior - por exemplo, o total dos gastos tributários no Brasil - para afirmar que as renúncias fiscais dirigidas à ZFM seriam reduzidas, ou um valor menor -

${ }^{18}$ Disponível em: https://cutt.ly/XrBkurB. Acesso em: 17 fev. 2020.

${ }^{19}$ Disponível em: https://cutt.ly/lrBkg5y. Acesso em: 17 fev. 2020. 
como a destinação anual de recursos para a Superintendência do Desenvolvimento do Nordeste (Sudene), por exemplo - para afirmar que seriam elevadas. ${ }^{20}$

Para estimar o custo total do PIM entre 2010 e 2011, Miranda (2013) considera três parcelas: i) os benefícios tributários da União destinados diretamente à ZFM; ii) os benefícios indiretos correspondentes aos incentivos fiscais concedidos às pessoas jurídicas sediadas na área de atuação da Superintendência do Desenvolvimento da Amazônia (Sudam); e iii) a restituição do Imposto sobre Operações relativas à Circulação de Mercadorias e Prestação de Serviços de Transporte Interestadual e Intermunicipal e de Comunicação (ICMS) concedida pelo Governo do Estado do Amazonas. A participação dos gastos tributários da União no total estimado por Miranda (2013) é da ordem de 80\%.

O principal questionamento dos gastos tributários dirigidos à ZFM reside em sua comparação com os benefícios potencialmente gerados. Considerando os dados mais recentes, somente as renúncias fiscais da União por emprego direto gerado superam $\mathrm{R} \$ 380$ mil por ano. Andrade, Gelcer e Holland (2019) assinalam que "é recorrente a crítica de que a Zona Franca de Manaus custa muito caro por emprego gerado" (os autores estimam um custo médio anual da ordem de $\mathrm{R} \$ 250$ mil por ano, contra um custo anual médio por emprego gerado da ordem de R $\$ 56$ mil na região). Andrade, Gelcer e Holland (2019) recorrem então ao multiplicador do emprego (4:1) mencionado acima para incluir os empregos indiretos nessa conta e, assim, argumentar que os benefícios seriam menores dos que os custos.

\section{Balança comercial}

Opostamente ao que se observa no caso das principais ZEE do mundo - cujo foco, conforme se mostrou na seção precedente, recai sobre as exportações -, o objetivo da ZFM (nos termos da própria legislação que a criou) é a promoção do desenvolvimento regional por meio da concessão de incentivos destinados à superação das desvantagens locacionais de Manaus (ou, mais genericamente, da Amazônia). Na prática, o modelo adotado acabou convertendo a ZFM em uma espécie singular de "zona de processamento de importações", uma vez que os incentivos fiscais oferecidos (incidentes, inclusive, sobre as matérias-primas importadas) favorecem o processamento local de componentes provenientes do exterior e sua subsequente comercialização no mercado interno. Esse é o

\footnotetext{
${ }^{20}$ Cavalcante (2018) calcula os custos das políticas de desenvolvimento regional no Brasil e assinala que "mais de 55\% desses custos são destinados à região Norte, especialmente em decorrência dos incentivos fiscais concedidos às empresas instaladas na Zona Franca de Manaus (ZFM)" (CAVALCANTE, 2018, p. 168).
} 
caso, por exemplo, dos produtos eletrônicos produzidos na região. Trata-se daquilo que Cano (2013, p. 77) apontou com uma peculiaridade da ZFM: "exportar para dentro".

Ao longo do período entre 2010 e 2018, a balança comercial da ZFM foi claramente deficitária, alcançando valores da ordem de US\$ 10 bilhões nos anos de maior crescimento da economia brasileira (durante os quais o mercado de consumo interno estava mais aquecido) e da ordem de US\$ 7 bilhões no período entre 2015 e 2018, quando o mercado interno se mostrou menos dinâmico. Em média, as exportações da ZFM, no período, representaram apenas $7,49 \%$ de suas importações. Trata-se, portanto, da importação de matérias primas usadas na produção de bens de consumo final comercializados no mercado interno, o que configura o caráter singular de "zona de processamento de importações" da ZFM. Esse modelo assemelha-se àquilo que Markusen (1996) chama de "plataforma satélite".

Miranda (2013) argumenta que enquanto as ZEE chinesas voltaram-se para as exportações e estiveram expostas a pressões competitivas, as empresas localizadas na ZFM atuam essencialmente no mercado doméstico e de forma protegida da concorrência externa, não tendo, desse modo, incentivos para ampliar seus níveis de competitividade.

Esse tipo de constatação nem sempre é bem acolhido por aqueles que defendem o modelo adotado na ZFM. Costa (2016, p. 22) registra que o rótulo de "maquiladora" é contestado pela Suframa, em cujo site se mencionam estudos que comprovariam que a ZFM seria "capaz de gerar e sustentar o crescimento por meio de suas economias de escala estáticas e dinâmicas" (SILVA; REIS, 2016). Contudo, o fato é que as economias de escala apontadas não habilitam a ZFM de prescindir dos incentivos fiscais que lhe são dirigidos, ainda que sua presença em si não possa ser considerada um problema (desde que, naturalmente, excedidos pelos impactos positivos eventualmente capazes de gerar).

\section{CONSIDERAÇÕES FINAIS}

Neste trabalho, apresentou-se uma revisão sistemática das principais estatísticas e dos principais resultados de trabalhos selecionados sobre a ZFM e, em particular, sobre o PIM. Argumentou-se que o conceito de ZEE acomoda múltiplos tipos de iniciativas. Ainda assim, de modo geral, seus impactos esperados envolvem o aumento dos níveis de competitividade, a atração de investimentos e a promoção do crescimento econômico. Registrou-se ainda que as ZEE formalmente estabelecidas no Brasil envolvem a ZFM, as ALC e as ZPE e que, nesse conjunto, destaca-se a ZFM, que tem o maior estoque de investimentos e que mobiliza os maiores níveis de benefícios fiscais. Do ponto de vista 
metodológico, buscou-se integrar os resultados de trabalhos independentes sobre o tema e, em particular, enfatizar os trabalhos em que se usam contrafactuais, regressões econométricas ou modelos de equilíbrio geral para avaliar os impactos da ZFM.

Os resultados indicam que:

- A ZFM tem impactos positivos nos níveis de renda e de bem-estar em Manaus, ainda que essa conclusão não seja unânime;

- Não há evidências conclusivas de que a ZFM contribui para a preservação ambiental da Amazônia;

- Os gastos tributários da União dirigidos à ZFM são estimados em R $\$ 28,7$ bilhões (mais de R $\$ 380$ mil por emprego direto gerado); e

- Embora o foco das ZEE recaia, de modo geral, sobre as exportações, o caso da ZFM é em grande medida singular em razão de seu foco no mercado interno.

O crescimento populacional - que foi explicitamente pretendido quando se criou a ZFM - ainda é eventualmente mencionado nas análises, embora, atualmente, a dimensão ambiental pareça ter mais relevância nas discussões sobre o tema do que a dimensão demográfica. Outros custos que vão além das renúncias fiscais (resultantes das distorções alocativas e de eventuais medidas de compensação) ainda são pouco explorados na produção bibliográfica sobre a ZFM. Esses aspectos podem ser objeto de trabalhos futuros sobre o tema.

De qualquer modo, este trabalho reafirma a percepção de que a ZFM é, do ponto de vista legal e do ponto de vista prático, essencialmente uma política de desenvolvimento regional (e não uma política de incentivo às exportações) e, portanto, não é diretamente comparável às ZEE exportadoras. No limite, a ZFM representa uma transferência líquida de recursos do país para Manaus. Essa constatação, em si, não embute um juízo de valor. Qualquer política regional envolve, na prática, algum tipo de transferência desse tipo. Isso explica, inclusive, porque parlamentares buscam beneficiar as regiões onde estão suas bases eleitorais por meio da criação de ZEE (CAVALCANTE, 2020). Contudo, políticas públicas em geral - e especialmente aquelas cujos custos não são desprezíveis - devem ser continuamente avaliadas.

É evidente que as avaliações de política jamais conseguirão ser absolutamente neutras, não só porque esse tipo de neutralidade é virtualmente impossível (especialmente na presença de impactos assimetricamente distribuídos no país), mas também porque o tema é multifacetado. Com efeito, mesmo análises precisas de custos e de benefícios precisariam levar em conta sua distribuição regionalmente assimétrica. Isso, contudo, não pode ser impedimento para que se busquem análises cada vez mais robustas para amparar 
decisões que, em última análise, terão uma forte componente política. Essa revisão sistemática é talvez um esforço nesse sentido.

\section{REFERÊNCIAS}

AMIRAHMADI, H.; WU, W. Export processing zones in Asia. Asian Survey, vol. XXXV, n. 9, set. 1995.

ANDRADE, J. M.; GELCER, D.; HOLLAND, M. Efetividade dos incentivos fiscais para a Zona Franca de Manaus. In: HOLLAND, M. (Coord.). Zona Franca de Manaus: impactos, efetividade e oportunidades. São Paulo: FGV/EESP, 2019. p. 53-65.

ARAÚJO, E. S. Desenvolvimento urbano local: o caso da Zona Franca de Manaus. Revista Brasileira de Gestão Urbana, Curitiba, v. 1, n. 1, p. 33-42, jan./jun. 2009.

BAENA, C. P. Revisão sistemática e metanálise: padrão ouro de evidência? Rev. Med. UFPR, v. 1, n. 2, p. 71-74, abr./jun. 2014.

BISPO, J. S. Criação e distribuição de riqueza pela Zona Franca de Manaus. 2009. 303 f. Tese (Doutorado em Controladoria e Contabilidade) - Faculdade de Economia, Administração e Contabilidade, Universidade de São Paulo, São Paulo, 2009.

BRASIL. [Constituição (1988)]. Constituição da República Federativa do Brasil [recurso eletrônico]. Brasília: Supremo Tribunal Federal, Secretaria de Documentação, 2019.

BRITO, C. F. M.; MACIEL, J. M. B. M. Fábricas selvagens: transformações do trabalho no Polo Industrial da Zona Franca de Manaus. Novos Cadernos NAEA, v. 22, n. 1, p. 137 158, jan./abr. 2019.

CANO, W. Amazônia: da crise à integração atípica e truncada. Am. Lat. Hist. Econ., v. 20, n. 2, p. 67-95, maio/ago. 2013.

CAVALCANTE, L. R. Políticas de desenvolvimento regional no Brasil: uma estimativa de custos. Revista Brasileira de Gestão e Desenvolvimento Regional (G\&DR), v. 14, n. 3, p. 147-171, maio/ago. 2018.

CAVALCANTE, L. R. Abrangência geográfica das políticas de desenvolvimento regional. Revista Brasileira de Gestão e Desenvolvimento Regional (G\&DR), v. 16, n. 2, p. 407-420, maio/ago. 2020.

CEPAL. Análise Ambiental e de Sustentabilidade do Estado do Amazonas. Santiago: Nações Unidas, 2007.

COSTA, J. B. O Polo Industrial da Zona Franca de Manaus e a preservação da floresta amazônica: caminhos independentes. 2016. 76 f. Dissertação (Mestrado em Sociedade e Cultura na Amazônia) - Instituto de Ciências Humanas e Letras, Universidade Federal do Amazonas, Manaus, 2016. 
FACCHINI, G.; WILLMANN, G. The gains from duty free zones. Journal of International Economics, v. 49, p. 403-412, 1999.

FAROLE, T. Special economic zones: what have we learned? Economic Premise (World Bank), n. 64, set. 2011.

FAROLE, T.; AKINCI, G. (Ed.). Special Economic Zones: Progress, Emerging Challenges, and Future Directions. Washington: The International Bank for Reconstruction and Development/The World Bank, 2011.

FAROLE, T.; MOBERG, L. Special economic zones in Africa: political economy challenges and solutions. In: PAGE, J. \& TARP, F. (Ed.). The practice of industrial policy: government - business coordination in Africa and East Asia. Oxford: Oxford University Press, 2017.

FIAS. Special Economic Zones: Performance, Lessons Learned, and Implications for Zone Development. Washington, D.C.: World Bank, 2008.

GONÇALVES, R. C. Uma análise econômica do modelo de desenvolvimento regional Zona Franca de Manaus. 2018. 76 f. Tese (Doutorado em Economia) - Escola de Gestão e Negócios, Universidade Católica de Brasília, Brasília, 2018.

GEBREWOLDE, T, M. Special Economic Zones Evidence and prerequisites for success. Ideas for Growth/International Growth Center (policy brief), 2009. Disponível em: <https://cutt.ly/wrGqx2P >. Acesso em: 28 jun. 2020.

GURGEL, A.; SERIGATTI, F. Impactos ambientais da Zona Franca de Manaus. In: HOLLAND, M. (Coord.). Zona Franca de Manaus: impactos, efetividade e oportunidades. São Paulo: FGV/EESP, 2019. p. 42-52.

HAUSMANN, R.; OBACH, J.; SANTOS, M. A. Special Economic Zones in Panama: a critical assessment. Cambridge (MA): Center for International Development, Harvard University, 2016.

HOLLAND, M. (Coord.). Zona Franca de Manaus: impactos, efetividade e oportunidades. São Paulo: FGV/EESP, 2019.

HOLLAND, M.; PIERI, R. Introdução. In: HOLLAND, M. (Coord.). Zona Franca de Manaus: impactos, efetividade e oportunidades. São Paulo: FGV/EESP, 2019. p. 10-11.

JAYANTHAKUMARAN, K. Benefit-cost appraisals of export processing zones: a survey of the literature. Development policy review, v. 21, n. 1, p. 51-65, 2003.

JOSHI, S. P.; NARKHEDE, P. A. Special Economic zones: issues \& implications. Dez. 2008.

LANNES JUNIOR, O. P. Zonas de livre comércio no mundo. Brasília: Câmara dos Deputados, nov. 2015 (estudo).

MARCHIORO, L. W. GUBERT, D.; GUBERT, V. A teoria dos polos de crescimento e desenvolvimento de Perroux e a implantação da Zona Franca de Manaus na região Norte do Brasil. Revista de Estudos Sociais, v. 16, n. 31, 2014. 
MARKUSEN, A. Sticky places in slippery space: a typology of industrial districts. Economic geography, v. 72, n. 3, p. 293-313, july 1996.

MIRANDA, R. N. Zona Franca de Manaus: desafios e vulnerabilidades. Brasília: Núcleo de Estudos e Pesquisa do Senado Federal, abr. 2013 (Texto para Discussão, n. 126).

MIYAGIWA, K. F. A reconsideration of the welfare economics of a free-trade zone. Journal of International Economics, v. 21, p. 337-350, 1986.

MOBERG, L. The political economy of special economic zones. Journal of institutional economics, v. 11, n. 1, p. 167-190, 2015.

MOTA, J. A.; CÂNDIDO JR, J. O. O efeito do PIM: análise contrafactual. In: RIVAS, A.; MOTA, J. A.; MACHADO, J. A. C. (Org.). Instrumentos econômicos para a proteção da Amazônia: a experiência do polo industrial de Manaus. Curitiba: Editora CRV, 2009. p. 144-156.

PIERI, R.; ALBUQUERQUE, P.; CERQUEIRA, C. Impactos socioeconômicos da Zona Franca de Manaus. In: HOLLAND, M. (Coord.). Zona Franca de Manaus: impactos, efetividade e oportunidades. São Paulo: FGV/EESP, 2019. p. 34-41.

POSSEBOM, V. Free Trade Zone of Manaus: an impact evaluation using the Synthetic Control Method. Revista Brasileira de Economia, v. 71, n. 2, p. 217-231, 2017.

PRINS, A. M.; COSTAS, R.; VAN LEEUWEN, T. N.; WOUTERS, P. F. Using Google Scholar in research evaluation of humanities and social science programs: a comparison with Web of Science data. Research evaluation, v. 25, n. 3, 2016.

REY, K. M. M.; CARDOSO JÚNIOR, J. C. P. A Zona Franca de Manaus pós Constituição Federal de 1988: trinta anos de desafios para a reinvenção do modelo de desenvolvimento da Amazônia. Ciência \& Trópico, Recife, v. 43, n. ed. especial, p. 227252, 2019.

RIVAS, A.; MOTA, J. A.; MACHADO, J. A. C. (Org.) Instrumentos econômicos para a proteção da Amazônia: a experiência do polo industrial de Manaus. Curitiba: Editora CRV, 2009.

SÁ, M. T. V.; MACHADO, J. A. C. Polo Industrial de Manaus (PIM): a medida de seu valor adicionado comparado ao resto do Brasil. 2012. Disponível em: $<\underline{\text { https://cutt.ly/miGx1fs }}>$. Acesso em: 28 jun. 2020.

SCHERER, E. F. Desemprego, trabalho precário e des-cidadanização na Zona Franca de Manaus. Somanlu, ano 4, n. 1, jan./jun. 2004.

SILVA, M. P. M. Impactos da reestruturação produtiva nas expressões de consciência de classe dos operadores de produção da Zona Franca de Manaus. Somanlu, ano 4, n. 1, jan./jun. 2004.

SILVA, R. R.; REIS, M. P. O. Modelo Zona Franca de Manaus: um estudo da sua

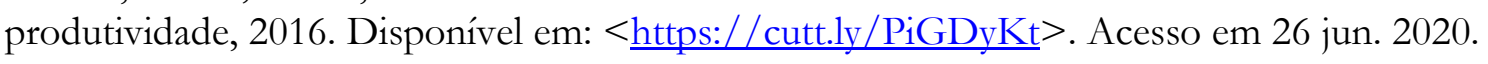


SOUZA, M. R.; RIBEIRO, A. L. P. Systematic review and meta-analysis of diagnostic and prognostic studies: a tutorial. Arq. Bras. Cardiol, v. 92, n. 3, p. 229-238, 2009.

UNCTAD. World investment report 2019: special economic zones. New York: Unctad, 2019.

\section{Como citar este artigo:}

\section{ABNT}

CAVALCANTE, L. R. Zona Franca de Manaus: uma revisão sistemática de impactos. InterEspaço: Revista de Geografia e Interdisciplinaridade, v. 6, e202001, 2020. Disponível em: <http://dx.doi.org/10.18764/2446-6549.e202001>. Acesso em: 25 jan. 2020.

\section{APA:}

Cavalcante, L. R. (2020). Zona Franca de Manaus: uma revisão sistemática de impactos. InterEspaco: Revista de Geografia e Interdisciplinaridade, v. 6, e202001. Recuperado em 25 janeiro, 2020, de http://dx.doi.org/10.18764/2446-6549.e202001

\section{@ccreative}

This is an open access article under the CC BY Creative Commons 4.0 license.

Copyright (C) 2020, Universidade Federal do Maranhão.

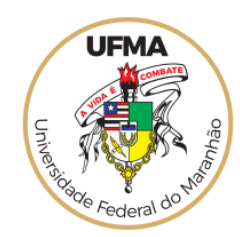

